\title{
Study on Urinary Tract Infection Among Females of Reproductive Age Group in Tertiary Care Teaching Hospital, Dhaka, Bangladesh
}

\author{
Sadia Saber, Naz Yasmin, Mohammed Tarek Alam, Mohammad Monower Hossain, Rafa Faaria Alam
}

\section{ABSTRACT}

Introduction: Among all the bacterial infections encounter in primary care, urinary tract infection (UTI) has considered as one of the most frequent bacterial infection. UTI can be defined as the presence of an infection in any part of our urinary system-kidneys, ureters, urinary bladder and urethra. Majority of the infections involve the lower urinary tract - the urinary bladder and the urethra. Women of reproductive age group (15-44 years) are the most vulnerable of developing UTI than men. The objective of this study is to determine the prevalence rate of UTI among females of reproductive age group and to ascertain the association between socio demographic factors among study population.

Material and Methods: This is a cross sectional observational study executed in a tertiary care teaching hospital, Dhanmondi, Dhaka. 250 women of reproductive age group were encountered as the study group here. Data collection was done by using a structured interview schedule followed by collection of urine sample for microscopic examination and culture. Analysis of data was done by using SPSS 15 software. Prevalence of UTI among study population was calculated by using percentage and the strength of association between socio demographic factors were evaluated in our study.

Results: Prevalence of UTI among study population was found to be $41.20 \%$. A strong association of statistical significance was observed among marital status ( $p$ values $<0.05$ ), the level of education of the study population ( $p$ value $<0.05$ ) and the urine culture reports among UTI patients ( $p$ value 0.001 )

Conclusion: Now a days UTI can be considered as one the most serious public health problem if it is remaining untreated. To prevent the possibilities of evolving further complexity of UTI early detection and prompt treatment is very much crucial. We should promote more educational programming about UTI prevention not only to reduce the sufferings of the patients and their hospital stay but also to compensate for the economical loss.

Keywords: Urinary tract infection, Women.
Published Online: January 26, 2021

ISSN: 2593-8339

DOI: 10.24018 /ejmed.2021.3.1.680

\section{Dr. Sadia Saber*}

MBBS, FCPS, MRCP (UK), MRCP (Ireland), MRCP (Glasgow), MACP (USA)

Assistant Professor, Department of

Medicine, Bangladesh Medical College,

Dhaka, Bangladesh.

(e-mail: sadiasaber201477@gmail.com)

Dr. Naz Yasmin

MBBS, FCPS, MS

Assistant Professor, Department of Gynae \& Obs., International Medical College, Dhaka, Bangladesh.

Dr. Mohammed Tarek Alam

MBBS, MD (USA)

Professor and Head, Department of Medicine, Bangladesh Medical College, Dhaka, Bangladesh.

Dr. Mohammad Monower Hossain MBBS

Medical Officer, Department of Medicine, Bangladesh Medical College Hospital, Dhaka, Bangladesh.

Dr. Rafa Faaria Alam MBBS

Assistant Registrar, Department of Medicine, Bangladesh Medical College Hospital, Dhaka, Bangladesh.

*Corresponding Author

\section{INTRODUCTION}

Worldwide women of all ages frequently encounter with urinary tract infection as the most popular non-intestinal disease [1]. UTI can be defined as the presence of microorganism in the urinary system [2], [3]. It can be categorized as the lower urinary tract infections, which involve the urinary bladder (cystitis), urethra (urethritis) and in case of male prostate (prostatitis), and upper urinary tract infections involving the kidneys (pyelonephritis) and ureter. UTI can be divided on the basis of the factors that trigger the infection as complicated or uncomplicated, depending on the nature of manifestations as recurrent or primary and along the clinical presentations as symptomatic or asymptomatic [4].

The spectrum of UTI symptoms ranges from a mild selflimiting illness i.e., burning sensation during micturition, bacteremia to severe sepsis with a mortality rate of $20-40 \%$ [5]-[7]. Typical symptoms of UTI include the triad of urgency (the enhanced desire to void the bladder), frequency (increased frequency of urination) and dysuria (painful urination). UTI is a wide term that encircles both asymptomatic bacteriuria and symptomatic infection with microbial invasion and inflammation of the urinary tract. While majority of the patients with UTI complain of urinary tract symptoms but around one third or more of the patients with these symptoms may not have any evidence of UTI in their routine urine analysis [8]. Asymptomatic bacteriuria, or asymptomatic urinary tract infection can be defined as a person without symptoms or signs of UTI but a specified quantitative count of bacteria that has been found in an appropriately collected urine specimen [9]. Globally around $2-10 \%$ prevalence of asymptomatic UTI has been observed among various researches [10]. Subsequently, symptomatic UTI are more frequently to come across among these particular group of asymptomatic patients [11]. If remain 
untreated or undertreated, then UTI can result into potentially serious life-threating sequelae.

UTI infects both males and females equally although women of reproductive age group (15-44years) remain mostly at risk. Various anatomical and physiological factors play a key role for developing UTI in women such as shorter length of urethra than males, absence of prostatic secretion, incomplete bladder emptying (either due to pregnancy or bladder, uterine or any other pelvic organ prolapse), sexually active females, easy contamination of urinary tract by the fecal flora, delay in micturition as a behavioral cause, use of diaphragm and condoms with spermicidal foams as contraceptives and due to loss of estrogen at the time of menopause [12]. The incidence of UTI has recorded among $1 \%$ of school going girls and around $4 \%$ among women with child bearing age. Various studies revealed that by considering several factors almost 25-30\% women of reproductive age group usually get UTI [3], [13].

Across the globe the microorganisms responsible for UTI remain constant. Among the all bacterial pathogens Escherichia coli has become the most prevailing organism (80-85\%) in charge of UTI. Other bacterial etiologies imply Staphylococcus saprophyticus (5-10\%), Proteus, Pseudomonas, Klebsiella, Enterobacter spp., Enterococcus Etc. [2], [14]. Virus executes a vital role in the pathophysiology of hemorrhagic cystitis although both viruses and parasites are not usually contemplated as urinary microbes [15].

Next to respiratory tract infections UTI has secured the the second most popular bacterial disease encounter in the primary care settings [2], [3]. Global statistics revealed that 8.3 million outpatient clinic visits are due to UTI, annually emergency department deals with 1 million UTI cases and around 100,000 patients got admitted to the hospitals due to complicated UTI [16]. UTI are likely to be more common in lower income countries like Bangladesh than other developed nations. The majority of the reports in the literature pertaining to urinary tract infections globally have measured asymptomatic or symptomatic UTI in pregnant women in comparison to the women of reproductive age group. With this background, this study was planned to find out the prevalence of UTI and its association with sociodemographic factors among females of the reproductive age group in tertiary care hospital, Bangladesh.

\section{MATERIALS AND METHODS}

\section{A. Study Design \& Area}

This a population based cross sectional observational study carried out in both Medicine and Gynecology departments of Bangladesh Medical College Hospital (BMCH) and International Medical College Hospital (IMCH) located at Dhanmondi and Gazipur area respectively in Bangladesh.

\section{B. Study Period}

This study was carried out from January 2020 - December 2020 .

\section{Sample Size}

In this study we have used the formula $4 \mathrm{PQ} / \mathrm{D}^{2}$ for calculating the sample size [17]. Here, $\mathrm{P}=$ Prevalence (previous studies), $\mathrm{Q}=100-\mathrm{P}, \mathrm{D}=$ allowable error $(5-20 \%$ of P). In one study of Nicolle et al, has revealed $10 \%$ prevalence of UTI in non-pregnant women which has chosen here for calculating prevalence as previous study source. By using this formula here, we found the sample size was 225 with $4 \%$ of absolute precision. Finally, the sample size was calculated to be 248 which was rounded off to 250 by adding $10 \%$ refusal rate.

\section{Inclusion Criteria}

Females with reproductive age group (15-44 years) visited to $\mathrm{BMCH} \& \mathrm{IMCH}$.

Patients who were apparently healthy and willing to participate in this study.

\section{E. Exclusion Criteria}

Females on any antibiotic medications.

Females on menstruation phase of the menstrual cycle.

Pregnant women.

Females with congenital urinary tract abnormalities.

Patients not willing to participate in the study.

Critically ill patients.

\section{F. Data Collection:}

Systematic random sampling technique was used to identify the study subjects. All the subjects underwent medical history assessment, general clinical examination, before enrollment. Patients gave informed consent before they participated in the study. Once informed consent was obtained, all participants were asked to complete a questionnaire to collect basic demographic information such as age, gender, place of living, marital status, clinical features. About $5 \mathrm{ml}$ of midstream urine was collected for microscopic analysis and cultured for finding presence of any microbes, by clean catch method in a sterile bottle. The sample processing was carried out within 2 hours of specimen collection. Microscopic examination of urine was done for pus cells. All samples were cultured on Mac Conkey agar plates. Incubation was done at $37^{\circ} \mathrm{C}$ aerobically for 12 24 hours.

\section{G. Operational Definition}

Asymptomatic UTI was defined as a patient without fever or clinical manifestations of UTI but there is presence of more than $1 \times 10^{5}$ colony forming unit (CFU) per milliliter of one organism in a culture of clean voided midstream urine [18].

Symptomatic UTI can be defined when any clinical features of UTI were present, and the colony count in a single culture was $10^{3}$ or more [19].

UTI should be considered when either of asymptomatic UTI or symptomatic bacteriuria was present [20].

Pure growth less than $1 \times 10^{3} \mathrm{CFU} / \mathrm{ml}$ was taken as growth of no significance [21].

\section{H. Data Analysis}

Data was recorded into semi-structured pre-tested pro forma. It was entered into Microsoft Excel and analyzed using SPSS v 16.0. Summarization of data was done 
according to data types and appropriate statistical tests were done. The various modes of clinical presentation were expressed as the total number of patients presenting with a particular presenting feature and then calculated as a percentage of the total number of patients. P-value of $<0.05$ was considered to be statically significant. Informed consent was taken in all the cases and the records were kept confidentially.

\section{Ethical Clearance and Informed Consent}

The study was carried out after obtaining approval from the Institutional Ethical Committee. The participants were briefed about the purpose of the study and informed consent was obtained prior to the data collection.

\section{RESULTS}

A. Prevalence of UTI (Both Symptomatic and Asymptomatic) among the Study Population

Among the females of reproductive age group, the prevalence of UTI was found to be 103(41.20\%) out of 250 patients (Fig. 1). 67 (65\%) UTI patients were symptomatic and $36(35 \%)$ were asymptomatic UTI cases (Fig. 2).

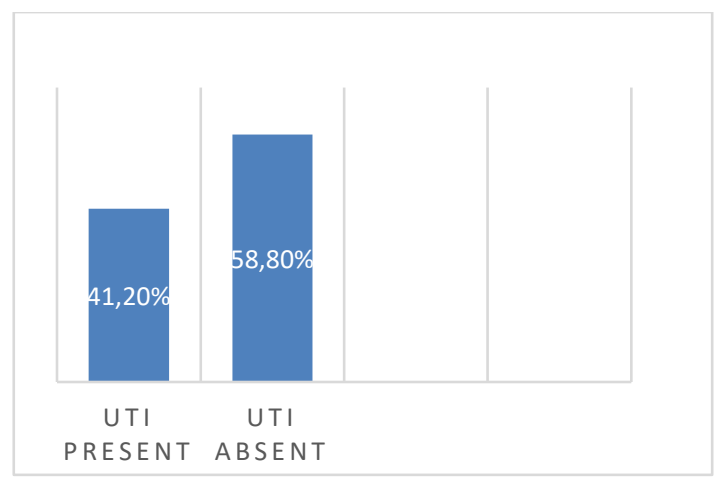

Fig. 1. Prevalence of UTI among study population $(n=250)$.

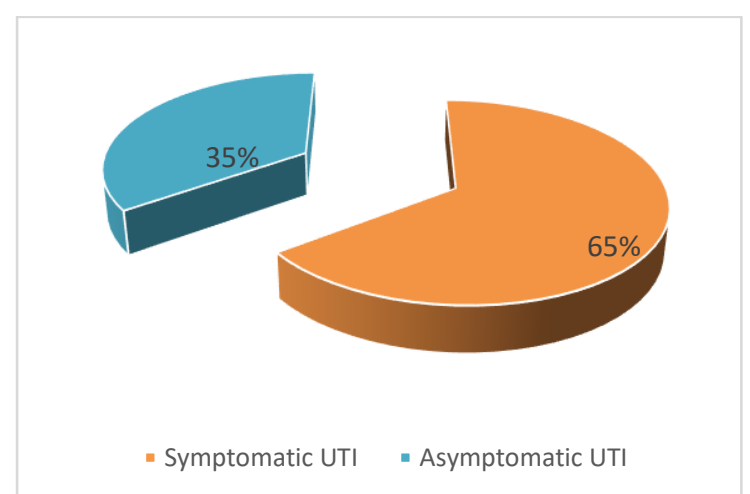

Fig. 2. Symptomatic and Asymptomatic UTI prevalence among study group.

\section{B. Age Wise Distribution of the Study Population}

In the study population majority of UTI patients belonged to the age group 30-44 years (57.28\%) (Table 1).

TABLE 1: Age Wise Distribution OF STUdy POPULATION

\begin{tabular}{ccccc}
\hline AGE & $\begin{array}{c}\text { Frequency } \\
(\mathrm{n}=250)\end{array}$ & $\begin{array}{c}\text { UTI Present } \\
(\mathrm{n}=103)\end{array}$ & $\begin{array}{c}\text { UTI Present } \\
(\%)\end{array}$ & p-value \\
\hline 15-29 years & 117 & 44 & 42.72 & 0.418 \\
30-44 years & 133 & 59 & 57.28 & \\
\hline
\end{tabular}

\section{Distribution of Study Population according to Religion}

Majority (55.33\%) UTI patients in our study were Muslim along with amalgamation of other religions have been observed (Table 2).

TABLE 2: RELIGION Wise DistribUtion OF STUdy POPULATION

\begin{tabular}{ccccc}
\hline Religion & $\begin{array}{c}\text { Frequency } \\
(\mathrm{n}=250)\end{array}$ & $\begin{array}{c}\text { UTI Present } \\
(\mathrm{n}=103)\end{array}$ & $\begin{array}{c}\text { UTI Present } \\
(\%)\end{array}$ & p-value \\
\hline Muslim & 133 & 57 & $55.33 \%$ & \\
Hindu & 67 & 31 & $30.09 \%$ & 0.264 \\
Christian & 27 & 8 & $7.78 \%$ & \\
Others & 23 & 7 & $6.8 \%$ & \\
\hline
\end{tabular}

D. Distribution of UTI Patients according to Educational Qualifications

In our study mainly literate patients were found to be suffering from UTI which has also revealed statistically significant ( $\mathrm{p}$ value $<0.01$ ) (Table 3 ).

TABLE 3: EduCATIONAL Status AMONG Study Population

\begin{tabular}{ccccc}
\hline $\begin{array}{c}\text { Educational } \\
\text { Status }\end{array}$ & $\begin{array}{c}\text { Frequency } \\
(\mathrm{n}=250)\end{array}$ & $\begin{array}{c}\text { UTI Present } \\
(\mathrm{n}=103)\end{array}$ & $\begin{array}{c}\text { UTI Present } \\
(\%)\end{array}$ & p-value \\
\hline Literate & 179 & 77 & 74.76 & 0.01 \\
Illiterate & 71 & 26 & 25.24 & \\
\hline
\end{tabular}

\section{E. Marital Status among Study Population}

Mostly married females of reproductive age group were found to be suffering from UTI rather than unmarried females [Table 4] which has proven statically significant in our study ( $\mathrm{p}$ value $<0.01$ ).

\begin{tabular}{ccccc}
\multicolumn{5}{c}{ TABLE 4: MARITAL STATUS AMONG STUDY POPULATION } \\
\hline Marital status & $\begin{array}{c}\text { Frequency } \\
(\mathrm{n}=250)\end{array}$ & $\begin{array}{c}\text { UTI Present } \\
(\mathrm{n}=103)\end{array}$ & $\begin{array}{c}\text { UTI Present } \\
(\%)\end{array}$ & p-value \\
\hline Married & 137 & 63 & 61.16 & \multirow{2}{*}{0.01} \\
Unmarried & 113 & 40 & 38.33 & \\
\hline
\end{tabular}

\section{F. Distribution of Clinical Features of UTI among Study Group}

Fig. 3 has revealed various clinical manifestations of UTI in our study population where $77 \%$ females were suffering from increased frequency of micturition, fever $63 \%$ and $59 \%$ with painful micturition. Although $35 \%$ females were asymptomatic during diagnosis.

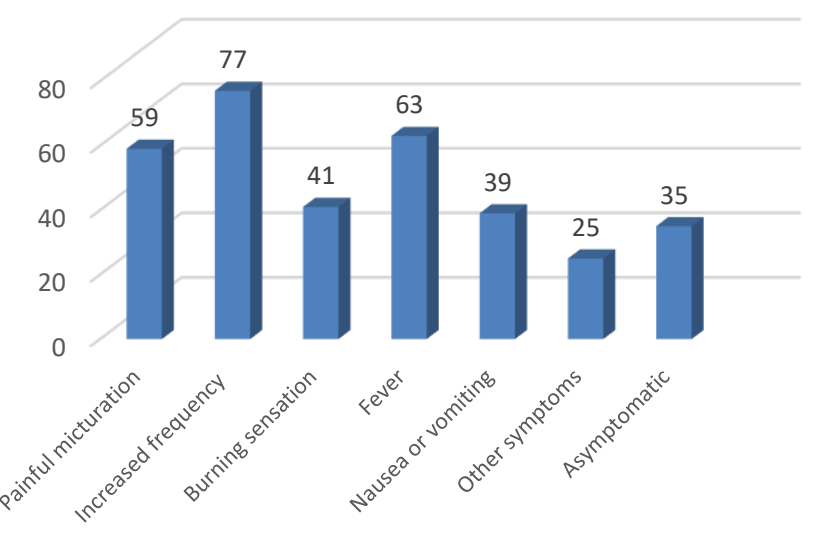

Fig. 3. Distribution of various clinical manifestations among UTI patients. 


\section{G. Urine Culture Results among Study Group}

The relationship between the presence of UTI symptoms and urine culture has revealed in Table 5. Positive urine culture has found among 43 symptomatic and 16 asymptomatic UTI patients which has shown statistical significance ( $\mathrm{p}$ value $<0.001)$.

TABLE 5: RELATIONSHIP BETWEEN UTI SYMPTOMS AND URINE CULTURE

\begin{tabular}{cccc}
\hline & $\begin{array}{c}\text { Culture } \\
\text { Positive }\end{array}$ & $\begin{array}{c}\text { Culture } \\
\text { Negative }\end{array}$ & P value \\
\hline $\begin{array}{c}\text { Symptomatic UTI } \\
(67)\end{array}$ & 43 & 24 & \\
$\begin{array}{c}\text { Asymptomatic UTI } \\
(36)\end{array}$ & 16 & 20 & 0.001 \\
\hline
\end{tabular}

Majority of the positive urine culture has shown growth of E. coli (64\%) infection and Staphylococcus spp. (19\%) (Fig. 4).

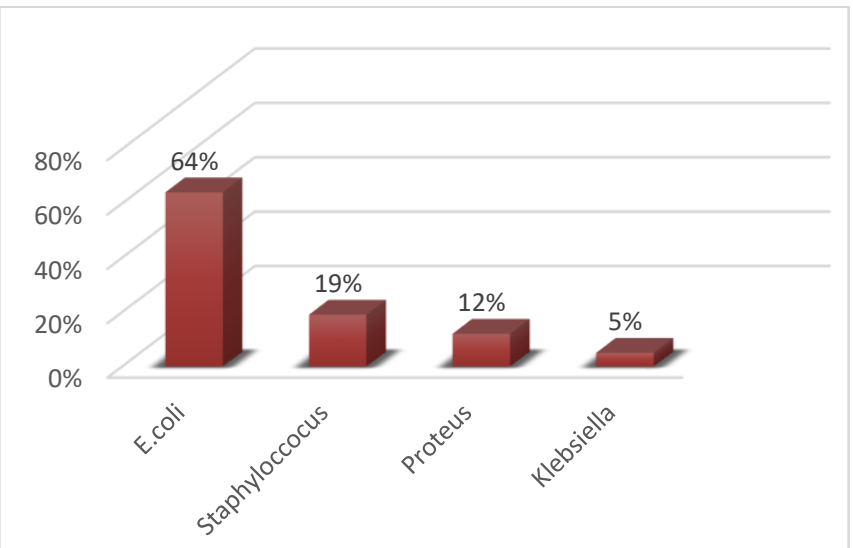

Fig. 4. Distribution of microorganisms causing UTI among study group.

\section{DISCUSSION}

In hospital settings UTI has considered the most frequent infection and in the general population it has secured the second position among all community acquired diseases. Around the globe every third women experience UTI at some point in their lifetime. Untreated and partially treated UTI may turn into a lot of complications and can create a great threat to the quality of life. It implies the major significance of early detection and appropriate treatment of UTI among patients at any age. In our study we tried to find out the prevalence of UTI among females of reproductive age group to provide the new vision regarding its early detection and management of this burning problem.

The socio demographic parameters highlighted in our study were found to be nearly comparable to the findings of other researches done elsewhere [22], [23]. Here we found around 58\% UTI patients belonged to the age group 30-44 years and $42.72 \%$ in 15-29 years. Among which majority $(55.33 \%)$ were Muslims in religion.

In the study population the prevalence of UTI was found to be $41.20 \%$ which has got a lot of similarities to the prevalence rate of another study done by Shaiful et al where the mentioned it was around $44.53 \%$. Other study done by Kolawole et al where they mentioned $60 \%$ prevalence rate among their UTI patients [24], [25]. These studies had got similarities in the prevalence rate of UTI because the selection of the study population which was hospital based and either the patients visited there with UTI symptoms or they acquired it through nosocomial infection.

Out of $41.20 \%$ patients who had UTI $65 \%$ were symptomatic and $35 \%$ were asymptomatic. In comparison this with another study where they found symptomatic UTI $76 \%$ and asymptomatic was $24 \%$ but their selection of study population was community based [26].

Medino-Bombardo et al. mentioned dysuria as the principle clinical manifestation of their study population in comparison to ours where it is $59 \%$ [27]. In another study they found $73.4 \%$ burning sensation during micturition, $43.9 \%$ had increased frequency and $20.1 \%$ had painful micturition [24] whereas in here we found increased frequency $77 \%$ and burning sensation $43 \%$. Some other studies also mentioned various clinical manifestations like fever, nausea, vomiting, groin pain, nocturnal incontinence, cloudy or bloody urine, fatigue and confusion [22], [24]. Their study population belonged from the tertiary care hospital like ours where the chances of various infections are more common.

In this study majority of the (43) symptomatic patients had culture positive in comparison to asymptomatic ones where it was only 16 culture positive cases. We found statistical significance between education and marital status of the patients. In one cohort study they found marital status as statistically significant among their UTI patients [23].

Here we found $64 \%$ E. coli, $19 \%$ Staphylococcus sp., $12 \%$ Proteus and 5\% Klebsiella growth from urine cultures with some similarities to another study where they found $61 \% \mathrm{E}$. coli, $12 \%$ Staphylococcus sp., $25 \%$ Proteus and $2 \%$ Klebsiella [26]. Different results have also demonstrated in another study where they found $33.1 \%$ E. coli, $7.9 \%$ Klebsiella, 2.2\% Staphylococcus sp. and 0.7\% Proteus [24].

\section{CONCLUSION}

Untreated and partially treated UTI can turn into a major public health problem with a lot of complications. We should provide emphasis regarding its early detection and appropriate treatment protocol. Females of reproductive age group should provide more information to create awareness and acquiring knowledge regarding its prevention as well. Efficient management of UTI can help us to bring a healthy and economically productive life in the community.

\section{ACKNOWLEDGEMENT}

The authors wish to thank Brig. Gen. Dr. Md. Abdus Sabur Miah (Retd), Director of Bangladesh Medical College Hospital for providing the facilities to complete the research work and grateful to the teaching staff of the laboratory for their help during the study. The authors also acknowledge the cooperation of the patients who participated in the study.

\section{REFERENCES}

[1] Dielubanza EJ (2011) Urinary tract infections in women. Med Clin North Am 95(1): 27-41.

[2] Pushpalatha KS. Urinary tract infection and management. J Nighting Nursing Times. 2008;4(5):28-32. 
[3] Hotchandani R, Aggarwal KK. Urinary Tract Infections in Women. Indian J Clin Practice. 2012;23(4):187-94.

[4] Vasudevan R. Urinary tract infection: an overview of the infection and the associated risk factors. J Microbiology Exp. 2014;1(2):1-5.

[5] Gonzalez CM, Schaeffer AJ. Treatment of urinary tract infection: what's old, what's new, and what works. World J Urol. 1999; 17:37282.

[6] Stamm WE, Hooton TM. Management of urinary tract infections in adults. N Eng J Med. 1993; 329:1328 -34.

[7] Foxman B. Epidemiology of urinary tract infections: incidence, morbidity, and economic costs. Disease- A-Month. 2003;49(2):53-70.

[8] Medina-Bambardo D, Segui-Diaz M, Roca-Fusalba C, Llobera J. The Dysuria Team. What is the predictive value of urinary symptoms for diagnosing urinary tract infection in women? J Family Pract. 2003; 20:103-7.

[9] Rubin RH, Shapiro ED, Andriole VT, Davis RJ, Stamm WE. Evaluation of new anti-infective drugs for the treatment of urinary tract infection. Clin Infect Dis. 1992;15(1):216-27.

[10] Dwyer PL, O'Reilly M. Recurrent urinary tract infection in the female. Current Opinion Obstetr Gynaecol. 2002; 14:537-43.

[11] Hooton TM, Scholes D, Stapleton AE, Roberts PL, Winter C, Gupta $\mathrm{K}$, et al. A prospective study of asymptomatic bacteriuria in sexually active young women. N Eng J Med. 2000; 343:992-7.

[12] Litza JA, Brill JR. Urinary tract infections. Primary Health Care. 2010;37(3):491-507.

[13] Wilma JP. Shafers Medical Surgical Nursing. 7th edition. New Delhi: B.I. Publications; 2002: 637- 640.

[14] John AS, Mboto CI, Agbo B. A review on the prevalence and predisposing factors responsible for urinary tract infection among adults. Eur J Experiment Biol. 2016;6(4):7-11.

[15] Chung A, Arianayagam M, Rashid, P. Australian Family Physician. 2010;39(5),295-8

[16] Naber KG, Schito G, Botto, H, Palou J. and Mazzei T. Surveillance study in Europe and Brazil on clinical aspects and Antimicrobial Resistance Epidemiology in Females with Cystitis (ARESC): implications for empiric therapy. Eur Urol. 2008;54(5):1164-75.

[17] Nicolle LE. Uncomplicated urinary tract infection in adults including uncomplicated pyelonephritis. Urologic Clin North Am. 2008;35(1):12.

[18] Delzell JE, Lefevre ML, Urinary tract infections during pregnancy. Am Family Physician. 2000; 61:713-21.

[19] Rubin RH, Beam TR Jr, Stamm WE. An approach to evaluating antibacterial agents in the treatment of urinary tract infection. Clin Infect Dis. 1992;14 Suppl 2:S246-51.

[20] Kant S, Lohiya A, Kapil A, Gupta SK. Urinary tract infection among pregnant women at a secondary level hospital in Northern India. Indian J Public Health. 2017;61(2):118.

[21] Khattak AM, Khattak S, Khan H, Ashiq B, Mohammad D, Rafiq M. Prevalence of asymptomatic bacteriuria in pregnant women. Pakistan J Med Sci. 2006;22(2):162.

[22] Subhashini N, Joby J, Latha A, Indira A. Assess the prevalence of urinary tract infection among patients admitted in tertiary care hospital at Nellore. Indian J Applied Res. 2016;2(6):865-6.

[23] Hooton TM, Scholes D, Hughes JP, Winter C, Roberts PL, Stapleton $\mathrm{AE}$, et al. A prospective study of risk factors for symptomatic urinary tract infection in young women. N Engl J Med. 1996;335(7):468-74.

[24] Shaifali I, Gupta U, Mahmood SE, Ahmed J. Antibiotic susceptibility patterns of urinary pathogens in female outpatients. North Am J Med Sci. 2012;4(4):163.

[25] Kolawole AS, Kolawole OM, Kandaki-Olukemi YT, Babatunde SK, Durowade KA, Kolawole CF. Prevalence of urinary tract infections (UTI) among patients attending Dalhatu Araf Specialist Hospital, Lafia, Nasarawa state, Nigeria. Int J Med Sci. 2010;1(5):163-7.

[26] Muthulakshmi M, Gopalakrishnan S. Study on urinary tract infection among females of reproductive age group ina rural area of Kancheepuram district, Tamil Nadu. Int J Community Med Public Health. 2017; Oct:4(10):3915-3921.

[27] Medina-Bombardo D, Segui-Diaz M, Roca-Fusalba C, Llobera J and the dysuria team (2003) What is the predictive value of urinary symptoms for diagnosing urinary tract infection in women? Fam Pract 20: 103-107. 